\title{
The Vasopressin System in the Risk of Diabetes and Cardiorenal Disease, and Hydration as a Potential Lifestyle Intervention
}

\author{
Sofia Enhörning ${ }^{a, b}$ Olle Melander ${ }^{a, c}$ \\ a Department of Clinical Sciences, Lund University, Malmö, Sweden; ${ }^{b}$ Department of Endocrinology, \\ Skåne University Hospital, Malmö, Sweden; ' Department of Internal Medicine, Skåne University Hospital, \\ Lund University, Malmö, Sweden
}

\section{Keywords \\ Vasopressin - Copeptin - Type 2 diabetes - Cardiovascular disease - Chronic kidney disease - Water intervention . \\ Hydration · Glucagon · Insulin · Glycemia}

\begin{abstract}
Background: Type 2 diabetes, chronic kidney disease (CKD) and its cardiovascular complications are increasing as health problems worldwide. These diseases are interrelated with overlapping occurrence and once diabetes is established, the risk of cardiorenal disease is dramatically elevated. Thus, a search for unifying modifiable risk factors is key for effective prevention. Summary: Elevated fasting plasma concentration of vasopressin, measured with the marker copeptin, predicts new onset type 2 diabetes as well as renal function decline. Furthermore, we recently showed that increased plasma copeptin concentration independently predicts the development of both CKD and other specified kidney diseases. In consequence, high copeptin is an independent risk factor for cardiovascular disease and premature mortality in both diabetes patients and in the general population. Vasopressin is released when plasma osmolality is high, and the easiest way to lower plasma vasopressin and copeptin con-
\end{abstract}

centration is to increase water intake. In a human water intervention experiment with 1 week of $3 \mathrm{~L} /$ day increased water intake, the one third of the participants with the greatest copeptin reduction (water responders) were those with a phenotype of low water intake (high habitual plasma copeptin and urine osmolality, and low urine volume). The water-responders had a copeptin reduction of $41 \%$ after 1 week of increased water intake compared to a control week; in contrast, a $3 \%$ reduction occurred in the other two thirds of the study participants. Among water responders, increased water intake also induced a reduction in fasting glucagon concentration. Key Messages: Elevated copeptin, a measure of vasopressin, is a risk marker of metabolic and cardiorenal diseases and may assist in the detection of individuals at higher risk for these diseases. Furthermore, individuals with high copeptin and other signs of low water intake may experience beneficial glucometabolic effects of increased water intake. Future randomized control trials investigating effects of hydration on glucometabolic and renal outcomes should focus on individuals with signs of low water intake including high plasma copeptin concentration.

(c) 2018 The Author(s)

Published by S. Karger AG, Basel

\begin{tabular}{ll}
\hline KARGER & $\begin{array}{l}\text { () } 2018 \text { The Author(s) } \\
\text { Published by S. Karger AG, Basel }\end{array}$ \\
E-Marger \\
E-Mail karger@karger.com & This article is licensed under the Creative Commons Attribution- \\
www.karger.com/anm & $\begin{array}{l}\text { NonCommercial-NoDerivatives 4.0 International License (CC BY- } \\
\text { NC-ND) (http://www.karger.com/Services/OpenAccessLicense). } \\
\text { Usage and distribution for commercial purposes as well as any dis- } \\
\text { tribution of modified material requires written permission. }\end{array}$
\end{tabular}

Sofia Enhörning

Department of Clinical Sciences, Clinical Research Center

Jan Waldenströms gata 35, 91:12, Skåne University Hospital

SE-205 02 Malmö (Sweden)

E-Mail sofia.enhorning@med.lu.se 


\section{Type 2 Diabetes, Cardiovascular and Renal Disease}

Type 2 diabetes is a growing problem worldwide. The cause of the epidemic increase is most likely a result from rapid changes in personal habits, including caloric overconsumption and decreasing physical activity; these trigger disease development in genetically predisposed individuals [1]. The dramatic increase in prevalence of type 2 diabetes leads to multiple complications and high healthcare costs. The late complications of diabetes include damage and failure of several organs. The microvascular damage of diabetes leads to retinopathy, neuropathy and nephropathy. However, most of the morbidity and mortality associated with diabetes is caused by macrovascular complications, including myocardial infarction and stroke $[2,3]$. The causes of the interaction between diabetes and cardiovascular disease (CVD) are incompletely understood, and studies have not consistently been able to show that improvement of glucose control in diabetes leads to decreased risk of CVD mortality $[4,5]$. Thus, it is relevant to find pharmacologically modifiable risk factors other than glucose level that are linked to CVD in diabetes patients, giving clinicians a possibility to slow or prevent disease development. Chronic kidney disease (CKD) and need for dialysis is also increasing as a health problem worldwide, and identification of the pathophysiological pathways contributing to CKD progression is crucial in order to find new preventive strategies.

\section{Vasopressin and Copeptin}

In recent years, it has been suggested that vasopressin may be a key player in the development of diabetes, renal disease and CVD.

Vasopressin, also called antidiuretic hormone, is a hormone secreted from the posterior pituitary to restore plasma osmolality. It is a short-lived hormone in plasma, with a mean half-life of $24 \mathrm{~min}$ [6]. Except from controlling plasma osmolality, vasopressin exerts a variety of different physiological effects in the body mediated through 3 receptors - the V1a receptor, the V1b recptor and the V2 receptor. The V1a receptor is widely expressed in the body and mediates, for example, vasoconstriction and platelet aggregation in blood vessels $[7,8]$, and glycogenolysis and gluconeogenesis in the liver $[9$, 10]. The V1b receptor is a component of the hypothalamic-pituitary-adrenocortical (HPA) axis. The receptor is expressed in the anterior pituitary gland and mediates release of adreno-corticothrophin hormone (ACTH).
This release, together with corticotrophin-releasing hormone $(\mathrm{CRH})$ effects, is important for the maintenance of ACTH and corticosterone levels in the endocrine stress response $[11,12]$. Vasopressin is also reported to be locally released within the adrenal gland, where it hypothetically mediates cortisol release and acts as a paracrine factor to stimulate adrenal steroidogenesis [13]. Furthermore, the $\mathrm{V} 1 \mathrm{~b}$ receptor is expressed in the pancreas where it mediates glucagon and insulin secretion [14, 15]. The antidiuretic action of vasopressin mainly depends on V2 receptor-mediated effects in the renal collecting duct [16].

The vasopressin precursor protein, prepro-vasopres$\sin$ (Fig. 1), is synthesized in magnocellular and parvocellular neurons of the hypothalamus and transported via axons to the posterior lobe of the pituitary gland, or released into the pituitary portal system to the anterior pituitary gland where it mediates ACTH release. During transport, prepro-vasopressin is cleaved into the product peptides vasopressin, neurophysin II and the C-terminal copeptin [17]. Neurophysin II is a carrier protein that serves to stabilize vasopressin during transport and storage, and to help in the correct folding and targeting of the vasopressin precursor $[17,18]$. Copeptin is also suggested to play a role in the correct folding and maturation of the vasopressin precursor [19], but the peptide has no other known physiological effects. All 3 peptides are released from the posterior pituitary gland when neurons in the hypothalamus are depolarized by osmoreceptor or baroreceptor stimuli $[17,20]$. The osmoreceptors, which are neurons in the lamina terminalis, are excluded from the blood brain barrier and thus are affected by changes in the concentration of systemic fluid solutes [21], thereby stimulating both thirst and vasopressin secretion during conditions of increased plasma osmolality. Sodium and its anions normally represent more than $95 \%$ of the osmotically active solutes in plasma; sodium is the most powerful solute to stimulate vasopressin release [22]. Vasopressin release is said to be suppressed to undetectable levels below a certain threshold level of osmolality (around 280 mosmol/L) [23, 24]. Above the threshold level, vasopressin is released proportionally to an increase in plasma osmolality (Fig. 2).

Because of its small size, it is not possible to detect vasopressin with sandwich immunoassays [25]. Thus, an assay was introduced in 2006 to quantify vasopressin release by the measurement of plasma copeptin (Fig. 1). Copeptin correlates well with vasopressin levels and can be measured reliably in plasma over a wide range of physiological changes in plasma osmolality [25-27] in indi- 
viduals with estimated glomerular filtration rate (eGFR) $>28 \mathrm{~mL} / \mathrm{min} / 1.73 \mathrm{~m}^{2}$. A correction for renal function may be required below this level of eGFR [28].

\section{Vasopressin and Diabetes}

It has been known since 1979 that individuals with diabetes have elevated vasopressin levels [29]. However, the exact causes of this elevation are not yet known. Recently it was discovered that diabetic rats, in contrast to control rats, have increased hypothalamic vasopressin synthesis due to upregulated chloride transporters and an excitatory response evoked by the neurotransmitter GABA. These findings thus reveal a potential mechanistic explanation for elevated vasopressin concentration in diabetes [30].

We and others previously showed that elevated fasting plasma concentration of vasopressin, measured as copeptin, strongly and independently predicts new onset type 2 diabetes [31-33] and is associated with all components of the metabolic syndrome (i.e., abdominal obesity, insulin resistance, hypertension, chronic inflammation and microalbuminuria) [34, 35]. Furthermore, a human Mendelian randomization study suggested causality between elevated vasopressin concentration and elevated plasma glucose concentration [36].

The mechanisms that underlie the vasopressin-associated development of metabolic diseases are not yet unravelled. Vasopressin mediates ACTH and cortisol release, enhances the effects of $\mathrm{CRH}$, and elevates glucocorticoid concentration in plasma upon stressful stimuli [11-13]. Furthermore, the vasopressin-induced ACTH release has been shown to be resistant to glucocorticoid feedback in contrast to the CRH-induced ACTH release [37], suggesting that excessive vasopressin release overstimulates the HPA axis. Elevated glucocorticoid concentration in plasma could explain the Cushing's syndrome-like phenotype seen in subjects with high copeptin including development of overweight and insulin resistance [38]. Other suggested links between the vasopressin system and metabolic disturbances include (a) Serum- and Glucocorticoidinducible Kinase 1, which is upregulated as part of the pleiotropic effects of glucocorticoids [39]; and (b) V1b receptor-mediated GLP-1 release from intestinal L-cells, which increases plasma glucocorticoid concentration and hypothetically modulates osmolality by a glucocorticoidmediated increase of intestinal sodium and water absorption [40]. Yet another potential link between vasopressin and metabolic disorders, which further adds to the complexity, is the influence of hydration status on modulation

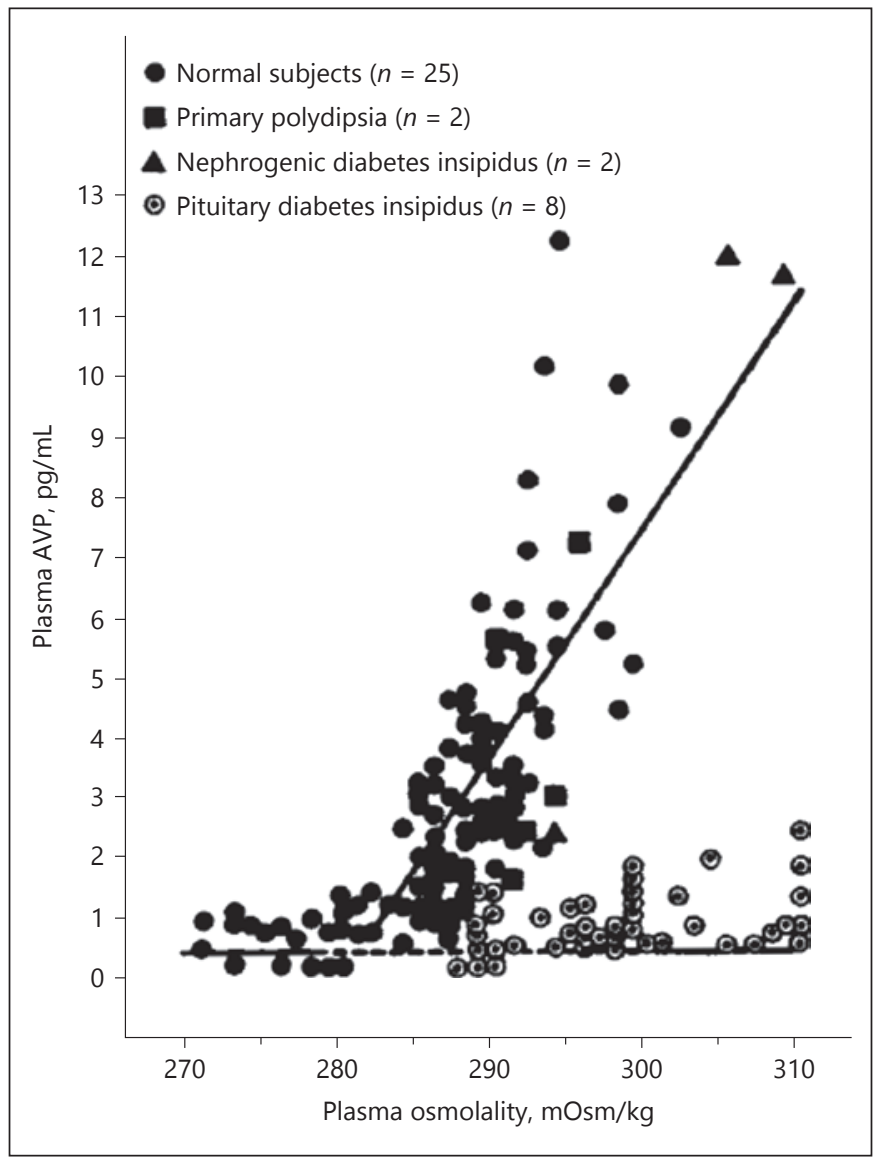

Fig. 1. Vasopressin (AVP) increases proportionally with the increase in plasma osmolality. Subjects with pituitary diabetes insipidus have an impaired vasopressin secretion, and subjects with nephrogenic diabetes insipidus have an impaired vasopressin function in the renal collecting duct. Reprinted from Robertson et al. [22] Copyright ${ }^{\circledR} 1976$, with permission from Elsevier.

of cell volume, which has been shown to change cellular metabolism. For example, hypoosmotic liver cell swelling decreases glycogenolysis and glycolysis in vitro [41].

\section{Potential Improvement of Glucose Metabolism and Cardiometabolic Health with Increased Hydration}

Previous trials and observational studies have demonstrated that high water intake may promote better glucose control, weight loss and decreased cardiovascular risk [42-45]. It is known that individuals with low water intake have elevated vasopressin concentrations [46], and we recently showed in healthy adults that increased water intake over 6 weeks effectively lowered circulating copeptin concentration [47]. A beneficial role of increased water 
Fig. 2. Vasopressin (AVP) is synthesized as part of a larger precursor protein, preproAVP. The vasopressin gene, encoding prepro-AVP, is located at chromosome 20. Numbers indicate amino acids. Exon 1 of the gene encodes the signal peptide of 19 amino acids, the nonapeptide vasopressin (AVP), and the N-terminal region of neurophysin II. Exon 2 encodes the central region of neurophysin II. Exon 3 encodes the C-terminal region of neurophysin II and a 39 amino acid glycopeptide known as copeptin. Figure adapted from [17] .

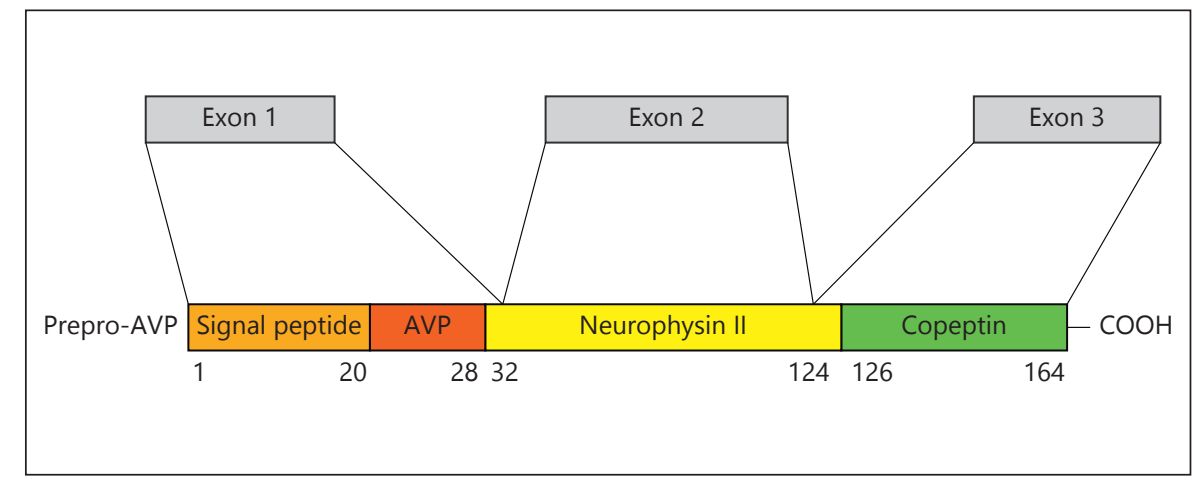

intake and decreased circulating vasopressin (measured as copeptin) for cardiometabolic health in humans was recently supported by animal studies where we showed not only that glucose tolerance in rats was impaired during sustained infusion of vasopressin but also that when rats had a high water intake, leading to low concentration of vasopressin, their insulin resistance and hepatic fat accumulation were reduced [48]. Conversely, a detrimental effect of 3 days of water restriction was demonstrated during an experimental study investigating glucose homeostasis in hypohydrated men with type 2 diabetes. In this study, impaired glucose regulation during an oral glucose tolerance test was paralleled by elevated plasma osmolality and cortisol concentrations, suggesting vasopressin-mediated ACTH and cortisol release [49]. In line with this finding, it is known that habitual low drinkers ( $\leq 1.2 \mathrm{~L}$ water/day) have elevated plasma cortisol concentration when compared to high drinkers (2-4 L water/day) [46].

\section{A Water Intervention Experiment}

To investigate the role of a decreased vasopressin load on glucose metabolism in humans we recently conducted a water intervention experiment [50]. Increased water intake was used to decrease plasma osmolality and thus vasopressin concentration in plasma. After a rapid oral water intake of $1 \mathrm{~L}$ in healthy adults $(n=37)$, copeptin decreased within minutes and remained low for several hours (Fig. 3). Furthermore, an excess intake of $3 \mathrm{~L}$ of water per day (above habitual water intake) during 1 week (water week) significantly lowered copeptin concentration. The one third of the participants with the greatest copeptin reduction after water week (water-responders) habitually exhibited a low water intake, high urine osmolality, low urine volume and high baseline copeptin. Furthermore, among water responders, a significantly lower fasting glucagon was observed after water week, compared to after a week of normal (habitual) water intake (control week).

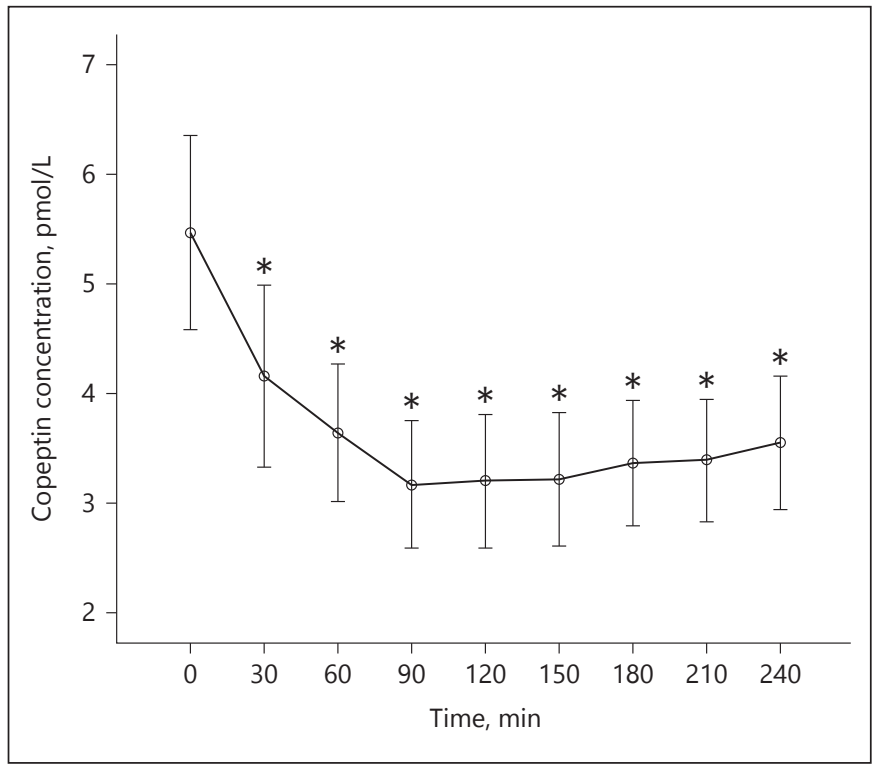

Fig. 3. Plasma copeptin concentration (expressed as mean [ $95 \%$ $\mathrm{CI}])$ measured minutes after $1 \mathrm{~L}$ water intake $(n=39)$. The median copeptin value at $0 \mathrm{~min}$ (not shown) was $5.05(3.53-6.44) \mathrm{pmol} / \mathrm{L}$, whereas it decreased to $2.77(2.28-3.57) \mathrm{pmol} / \mathrm{L}$ at $90 \mathrm{~min} .{ }^{*} p<$ 0.001. Reprinted from Enhörning et al. [50] Copyright ${ }^{\complement} 2017$.

These data suggest that individuals with elevated copeptin, and thus higher risk for metabolic diseases, may experience improved gluco-regulation following increased water intake.

\section{Vasopressin in Renal Disease and the Role of Hydration on Kidney Health}

A randomized controlled water intake trial, examining the effects of increased water intake on eGFR in subjects with CKD, was recently completed [51]. In line with the epidemiological findings of a kidney protective hydration 
effect $[52,53]$, previous experimental studies in humans and animals suggest beneficial effects on kidney function from increased water intake [54], genetic lack of vasopressin $[55,56]$, and vasopressin receptor antagonism [57]; in contrast, impaired renal function has been observed during vasopressin exposure [55, 58]. Furthermore, we and others have shown that elevated copeptin, as a proxy for low water intake, is associated with microalbuminuria $[32,59]$ and independently predicts renal function decline, measured as decline in eGFR, in diabetes patients $[60-62]$ and in the general population [63, 64].

We recently extended our previous finding that copeptin predicts eGFR decline by showing that elevated baseline copeptin was independently associated with increased risk of CKD development in 2 population-based Swedish cohorts [65]. The Malmö Preventive Project (MPP) and Malmö Diet and Cancer Cardiovascular Cohort (MDC-CC) were followed for 9 and 20 years, respectively, and incident cases of renal disease were identified by national registers covering $99 \%$ of all hospital discharges, hospital-based outpatient care, and all deaths among Swedish residents. Furthermore, in the MPP cohort and in a meta-analysis of the MPP and MDC-CC cohorts, association between elevated copeptin and increased risk of specified kidney diseases other than CKD was observed. Among this set of widely diverse diagnoses, the most frequently occurring specified kidney disease diagnoses were acute tubulointerstitial nephritis and hydronephrosis in both of the cohorts. In a subanalysis, we found that elevated copeptin mainly increased the risk of tubulointerstitial kidney disease, a finding that was hypothetically linked to the fact that the V2R are localized in the tubuli.

These convincing epidemiological and experimental data point at a causal link between high circulating vasopressin concentration and renal disease, even though large randomized controlled trials to test if lowering or blocking of vasopressin is renoprotective are needed to understand whether the link is causal or not. Similar to the vasopressin-associated development of diabetes and the metabolic syndrome, the mechanisms that underlie the vasopressin-associated development of renal disease are not known. However, studies in rats have shown that vasopressin induces an increase of renal plasma flow and glomerular filtration rate (hyperfiltration), which is thought to be at least partially involved $[56,66]$. Interestingly, chronic exposure to elevated glucocorticoids in patients with Cushing's syndrome causes a decreased glomerular filtration rate [67], suggesting that excessive vasopressin release followed by overstimulation of the HPA axis may not only be linked to the development of the metabolic syndrome, as described above, but also to renal function decline.

\section{Conclusion}

Elevated vasopressin is an independent risk factor for the development of diabetes and cardiorenal disease, and extensive epidemiological and experimental data suggest a causal link. In the future, the vasopressin marker copeptin may help detect individuals who are at higher risk for disease development and who might benefit from vasopressin-lowering therapy and lifestyle interventions such as increased hydration.

\section{Acknowledgment}

This article was supported by ALF-funds and a grant from the ISN-H4KH Initiative.

\section{Disclosure Statement}

Dr. Enhörning received registration fee and travel expenses from Danone Nutricia Research. Dr. Melander received a research grant and consultancy fee from Danone Nutricia Research. The authors report no other conflicts of interest in this work.

\section{References}

1 Parikh H, Groop L: Candidate genes for type 2 diabetes. Rev Endocr Metab Disord 2004;5: 151-176.

2 Berry J, Keebler ME, McGuire DK: Diabetes mellitus and cardiovascular disease. Pandora's box has been opened. Herz 2004;29:456462 .

3 Zimmet P, Alberti KG, Shaw J: Global and societal implications of the diabetes epidemic. Nature 2001;414:782-787.

Vasopressin, Diabetes and Cardiorenal Disease
4 Gerstein HC, Miller ME, Byington RP, Goff DC Jr, Bigger JT, Buse JB, Cushman WC, Genuth S, Ismail-Beigi F, Grimm RH Jr, et al: Effects of intensive glucose lowering in type 2 diabetes. N Engl J Med 2008;358:25452559

5 ADVANCE Collaborative Group, Patel A, MacMahon S, Chalmers J, Neal B, Billot L, Woodward M, Marre M, Cooper M, Glasziou $\mathrm{P}$, et al: Intensive blood glucose control and vascular outcomes in patients with type 2 diabetes. N Engl J Med 2008;358:25602572.

6 Baumann G, Dingman JF: Distribution, blood transport, and degradation of antidiuretic hormone in man. J Clin Invest 1976;57:1109-1116.

7 Ohlstein EH, Berkowitz BA: Human vascular vasopressin receptors: analysis with selective vasopressin receptor antagonists. J Pharmacol Exp Ther 1986;239:737-741. 
8 Filep J, Rosenkranz B: Mechanism of vasopressin-induced platelet aggregation. Thromb Res 1987;45:7-15.

9 Whitton PD, Rodrigues LM, Hems DA: Stimulation by vasopressin, angiotensin and oxytocin of gluconeogenesis in hepatocyte suspensions. Biochem J 1978;176:893-898.

10 Keppens S, de Wulf $\mathrm{H}$ : The nature of the hepatic receptors involved in vasopressin-induced glycogenolysis. Biochim Biophys Acta 1979;588:63-69.

11 Tanoue A, Ito S, Honda K, Oshikawa S, Kitagawa Y, Koshimizu TA, Mori T, Tsujimoto G: The vasopressin V1b receptor critically regulates hypothalamic-pituitary-adrenal axis activity under both stress and resting conditions. J Clin Invest 2004;113:302-309.

12 Antoni FA: Vasopressinergic control of pituitary adrenocorticotropin secretion comes of age. Front Neuroendocrinol 1993;14:76-122.

13 Perraudin V, Delarue C, Lefebvre H, Contesse V, Kuhn JM, Vaudry H: Vasopressin stimulates cortisol secretion from human adrenocortical tissue through activation of V1 receptors. J Clin Endocrinol Metab 1993;76:1522-1528.

14 Abu-Basha EA, Yibchok-Anun S, Hsu WH Glucose dependency of arginine vasopressininduced insulin and glucagon release from the perfused rat pancreas. Metabolism 2002;51: 1184-1190.

15 Spruce BA, McCulloch AJ, Burd J, Orskov H, Heaton A, Baylis PH, Alberti KG: The effect of vasopressin infusion on glucose metabolism in man. Clin Endocrinol 1985;22:463468.

16 Bankir L: Antidiuretic action of vasopressin quantitative aspects and interaction between V1a and V2 receptor-mediated effects. Cardiovasc Res 2001;51:372-390.

17 Di Iorgi N, Napoli F, Allegri AE, Olivieri I, Bertelli E, Gallizia A, Rossi A, Maghnie M: Diabetes insipidus - diagnosis and management. Horm Res Paediatr 2012;77:69-84.

18 Eubanks S, Nguyen TL, Deeb R, Villafania A, Alfadhli A, Breslow E: Effects of diabetes insipidus mutations on neurophysin folding and function. J Biol Chem 2001;276:2967129680.

19 Barat C, Simpson L, Breslow E: Properties of human vasopressin precursor constructs: inefficient monomer folding in the absence of copeptin as a potential contributor to diabetes insipidus. Biochemistry 2004;43:8191-8203.

20 Morgenthaler NG: Copeptin: a biomarker of cardiovascular and renal function. Congest Heart Fail 2010;16(suppl 1):S37-S44.

21 Holmes CL, Landry DW, Granton JT: Science review: Vasopressin and the cardiovascular system part 1 - receptor physiology. Critical Care 2003;7:427-434.

22 Robertson GL, Shelton RL, Athar S: The osmoregulation of vasopressin. Kidney Int 1976;10:25-37.

23 Fressinaud P, Corvol P, Menard J: Radioimmunoassay of urinary antidiuretic hormone in man: stimulation-suppression tests. Kidney Int 1974;6:184-190.
24 Robertson GL, Mahr EA, Athar S, Sinha T: Development and clinical application of a new method for the radioimmunoassay of arginine vasopressin in human plasma. J Clin Invest 1973;52:2340-2352.

25 Morgenthaler NG, Struck J, Alonso C, Bergmann A: Assay for the measurement of copeptin, a stable peptide derived from the precursor of vasopressin. Clin Chem 2006;52: 112-119.

26 Morgenthaler NG, Struck J, Jochberger S, Dunser MW: Copeptin: clinical use of a new biomarker. Trends Endocrinol Metab 2008; 19:43-49.

27 Balanescu S, Kopp P, Gaskill MB, Morgenthaler NG, Schindler C, Rutishauser J: Correlation of plasma copeptin and vasopressin concentrations in hypo-, iso-, and hyperosmolar States. J Clin Endocrinol Metab 2011; 96:1046-1052.

28 Ettema EM, Heida J, Casteleijn NF, Boesten L, Westerhuis R, Gaillard C, Gansevoort RT, Franssen CFM, Zittema D: The effect of renal function and hemodialysis treatment on plasma vasopressin and copeptin levels. Kidney Int Rep 2017;2:410-419.

29 Zerbe RL, Vinicor F, Robertson GL: Plasma vasopressin in uncontrolled diabetes mellitus. Diabetes 1979;28:503-508.

30 Kim YB, Kim WB, Jung WW, Jin X, Kim YS, Kim B, Han HC, Block GD, Colwell CS, Kim YI: Excitatory GABAergic action and increased vasopressin synthesis in hypothalamic magnocellular neurosecretory cells underlie the high plasma level of vasopressin in diabetic rat. Diabetes 2018;67:486-495.

31 Enhorning S, Wang TJ, Nilsson PM, Almgren P, Hedblad B, Berglund G, Struck J, Morgenthaler NG, Bergmann A, Lindholm E, et al: Plasma copeptin and the risk of diabetes mellitus. Circulation 2010;121:2102-2108.

32 Enhorning S, Bankir L, Bouby N, Struck J, Hedblad B, Persson M, Morgenthaler NG, Nilsson PM, Melander O: Copeptin, a marker of vasopressin, in abdominal obesity, diabetes and microalbuminuria: the prospective Malmo Diet and Cancer Study cardiovascular cohort. Int J Obes (Lond) 2013;37:598-603.

33 Abbasi A, Corpeleijn E, Meijer E, Postmus D, Gansevoort RT, Gans RO, Struck J, Hillege HL, Stolk RP, Navis G, et al: Sex differences in the association between plasma copeptin and incident type 2 diabetes: the Prevention of Renal and Vascular Endstage Disease (PREVEND) study. Diabetologia 2012;55:19631970 .

34 Saleem U, Khaleghi M, Morgenthaler NG, Bergmann A, Struck J, Mosley TH Jr, Kullo IJ: Plasma carboxy-terminal provasopressin (copeptin): a novel marker of insulin resistance and metabolic syndrome. J Clin Endocrinol Metab 2009;94:2558-2564

35 Enhorning S, Struck J, Wirfalt E, Hedblad B, Morgenthaler NG, Melander O: Plasma copeptin, a unifying factor behind the metabolic syndrome. J Clin Endocrinol Metab 2011; 96:E1065-E1072.
36 Roussel R, El Boustany R, Bouby N, Potier L, Fumeron F, Mohammedi K, Balkau B, Tichet J, Bankir L, Marre M, et al: Plasma copeptin, AVP gene variants, and incidence of type 2 diabetes in a cohort from the community. J Clin Endocrinol Metab 2016;101:2432-2439.

37 Rabadan-Diehl C, Aguilera G: Glucocorticoids increase vasopressin $\mathrm{V} 1 \mathrm{~b}$ receptor coupling to phospholipase C. Endocrinology 1998; 139:3220-3226

38 Anagnostis P, Athyros VG, Tziomalos K, Karagiannis A, Mikhailidis DP: Clinical review: The pathogenetic role of cortisol in the metabolic syndrome: a hypothesis. J Clin Endocrinol Metab 2009;94:2692-2701.

39 L, Guelinckx I, Lemetais G, Melander O: Two liters a day keep the doctor away? Considerations on the pathophysiology of suboptimal fluid intake in the common population. Kidney Blood Press Res 2017;42:483-494.

40 Pais R, Rievaj J, Meek C, De Costa G, Jayamaha S, Alexander RT, Reimann F, Gribble F: Role of enteroendocrine L-cells in arginine vasopressin-mediated inhibition of colonic anion secretion. J Physiol 2016;594:48654878.

41 Haussinger D: The role of cellular hydration in the regulation of cell function. The Biochem J 1996;313(Pt 3):697-710.

42 Chan J, Knutsen SF, Blix GG, Lee JW, Fraser GE: Water, other fluids, and fatal coronary heart disease: the Adventist Health Study. Am J Epidemiol 2002;155:827-833.

43 Dennis EA, Dengo AL, Comber DL, Flack KD, Savla J, Davy KP, Davy BM: Water consumption increases weight loss during a hypocaloric diet intervention in middle-aged and older adults. Obesity (Silver Spring) 2010; 18:300-307.

44 Roussel R, Fezeu L, Bouby N, Balkau B, Lantieri O, Alhenc-Gelas F, Marre M, Bankir L; D.E.S.I.R. Study Group: Low water intake and risk for new-onset hyperglycemia. Diabetes Care 2011;34:2551-2554.

45 Stookey JD, Constant F, Popkin BM, Gardner $\mathrm{CD}$ : Drinking water is associated with weight loss in overweight dieting women independent of diet and activity. Obesity (Silver Spring) 2008;16:2481-2488.

46 Perrier E, Vergne S, Klein A, Poupin M, Rondeau P, Le Bellego L, Armstrong LE, Lang F, Stookey J, Tack I: Hydration biomarkers in free-living adults with different levels of habitual fluid consumption. Br J Nutr 2013;109: 1678-1687.

47 Lemetais G, Melander O, Vecchio M, Bottin $\mathrm{JH}$, Enhorning S, Perrier ET: Effect of increased water intake on plasma copeptin in healthy adults. Eur J Nutr 2017, Epub ahead of print.

48 Taveau C, Chollet C, Waeckel L, Desposito D, Bichet DG, Arthus MF, Magnan C, Philippe E, Paradis V, Foufelle F, et al: Vasopressin and hydration play a major role in the development of glucose intolerance and hepatic steatosis in obese rats. Diabetologia 2015;58: 1081-1090. 
49 Johnson EC, Bardis CN, Jansen LT, Adams JD, Kirkland TW, Kavouras SA: Reduced water intake deteriorates glucose regulation in patients with type 2 diabetes. Nutr Res 2017; 43:25-32.

50 Enhorning S, Tasevska I, Roussel R, Bouby N, Persson M, Burri P, Bankir L, Melander O: Effects of hydration on plasma copeptin, glycemia and gluco-regulatory hormones: a water intervention in humans. Eur J Nutr 2017, Epub ahead of print.

51 Clark WF, Sontrop JM, Huang SH, Gallo K, Moist L, House AA, Weir MA, Garg AX: The chronic kidney disease Water Intake Trial (WIT): results from the pilot randomised controlled trial. BMJ Open 2013;3:e003666.

52 Clark WF, Sontrop JM, Macnab JJ, Suri RS, Moist L, Salvadori M, Garg AX: Urine volume and change in estimated GFR in a community-based cohort study. Clin J Am Soc Nephrol 2011;6:2634-2641.

53 Strippoli GF, Craig JC, Rochtchina E, Flood VM, Wang JJ, Mitchell P: Fluid and nutrient intake and risk of chronic kidney disease. Nephrology (Carlton) 2011;16:326-334.

54 Bouby N, Bachmann S, Bichet D, Bankir L: Effect of water intake on the progression of chronic renal failure in the 5/6 nephrectomized rat. Am J Physiol 1990;258(4 Pt 2): F973-F979.

55 Bouby N, Hassler C, Bankir L: Contribution of vasopressin to progression of chronic renal failure: study in Brattleboro rats. Life Sci 1999; 65:991-1004
56 Bardoux P, Martin H, Ahloulay M, Schmitt F, Bouby N, Trinh-Trang-Tan MM, Bankir L: Vasopressin contributes to hyperfiltration, albuminuria, and renal hypertrophy in diabetes mellitus: study in vasopressin-deficient Brattleboro rats. Proc Natl Acad Sci U S A 1999; 96:10397-10402.

57 Perico N, Zoja C, Corna D, Rottoli D, Gaspari F, Haskell L, Remuzzi G: V1/V2 Vasopressin receptor antagonism potentiates the renoprotection of renin-angiotensin system inhibition in rats with renal mass reduction. Kidney Int 2009;76:960-967.

58 Bardoux P, Bichet DG, Martin H, Gallois Y, Marre M, Arthus MF, Lonergan M, Ruel N, Bouby N, Bankir L: Vasopressin increases urinary albumin excretion in rats and humans: involvement of $\mathrm{V} 2$ receptors and the reninangiotensin system. Nephrol Dial Transplant 2003;18:497-506.

59 Meijer E, Bakker SJ, Halbesma N, de Jong PE, Struck J, Gansevoort RT: Copeptin, a surrogate marker of vasopressin, is associated with microalbuminuria in a large population $\mathrm{CO}^{-}$ hort. Kidney Int 2010;77:29-36.

60 Pikkemaat M, Melander O, Bengtsson Bostrom K: Association between copeptin and declining glomerular filtration rate in people with newly diagnosed diabetes. The Skaraborg Diabetes Register. J Diabetes Complications 2015;29:1062-1065.

61 Boertien WE, Riphagen IJ, Drion I, Alkhalaf A, Bakker SJ, Groenier KH, Struck J, de Jong PE, Bilo HJ, Kleefstra N, et al: Copeptin, a sur- rogate marker for arginine vasopressin, is associated with declining glomerular filtration in patients with diabetes mellitus (ZODIAC-33). Diabetologia 2013;56:1680-1688.

62 Velho G, El Boustany R, Lefevre G, Mohammedi K, Fumeron F, Potier L, Bankir L, Bouby N, Hadjadj S, Marre M, et al: Plasma copeptin, kidney outcomes, ischemic heart disease, and all-cause mortality in people with long-standing type 1 diabetes. Diabetes Care 2016;39:2288-2295.

63 Roussel R, Matallah N, Bouby N, El Boustany R, Potier L, Fumeron F, Mohammedi K, Balkau B, Marre M, Bankir L, et al: Plasma copeptin and decline in renal function in a cohort from the community: the prospective D.E.S.I.R. Study. Am J Nephrol 2015;42:107-114.

64 Tasevska I, Enhorning S, Christensson A, Persson $\mathrm{M}$, Nilsson PM, Melander O: Increased levels of copeptin, a surrogate marker of arginine vasopressin, are associated with an increased risk of chronic kidney disease in a general population. Am J Nephrol 2016;44:22-28.

65 Enhörning S, Christensson A, Melander O Plasma copeptin as a predictor of kidney disease. Nephrol Dial Transplant 2018, Epub ahead of print.

66 Bouby N, Ahloulay M, Nsegbe E, Dechaux M, Schmitt F, Bankir L: Vasopressin increases glomerular filtration rate in conscious rats through its antidiuretic action. J Am Soc Nephrol 1996;7:842-851.

67 Smets P, Meyer E, Maddens B, Daminet S: Cushing's syndrome, glucocorticoids and the kidney. Gen Comp Endocrinol 2010;169:1-10. 